\title{
Reflexiones acerca de la vida de cada día en la Ucrania post-sovietica
}

\section{Oscar Plaza}

El autor; clespués de pasar un año en Ucrania, como Profesor Visitante, reflexiona acerca de la realidad social, política y económica en ese país. A pesar de estar consciente de que hoy se habla de postmodernismo, considera a Ucrania como una sociedad industrial, pero no modema, ya que carece de los procedimientos, valores y comodidades de la modernidad. Constata, además, el fracaso absoluto del modelo de industrialización comunista. Finalmente, estima que la politica doméstica, con un necesario y reforzado Estado de Derecho, y sus relaciones internacionales, especialmente las vecinales, definirán el futuro de Ucrania.

\section{Introducción}

Este trabajo intenta resumir lo aprendido durante un año académico como profesor visitante en Ucrania, como así también en mis discusiones posteriores con los colegas que vivieron conmigo dicha experiencia. Mi visión de la Ucrania post-soviética y post-comunista debe ponerse en el contexto de mi doble trasfondo cultural: el chileno y el estadounidense.

Como introducción a la complejidad de la sociedad ucraniana, permítaseme omitir el nombre de la ciudad en la cual permanecí enseñando dado que me resulta muy difícil resumir en pocas palabras las razones históricas por las cuales la ciudad es conocida por cuatro nombres diferentes en cuatro diferentes lenguas. Ucranianos, rusos, polacos, alemanes, y austríacos, tienen lazos históricos con esta ciudad ubicada en la Ucrania occidental.

Un inmediato e ilustrativo encuentro con el colapso del comunismo soviético nos fue ofrecido en el mismo aeropuerto internacional de Kiev. No se podía cruzar el umbral de la puerta principal del edificio central del aeropuerto porque se estaba cayendo a pedazos. Pronto aprendimos que este hecho era lugar común en todo el país. 
Cuando mi esposa y yo fuimos informados de que mi nombramiento era en una universidad ucraniana, nuestra primera preocupación fue nuestra hija de tres años. Cómo llegamos a nuestro destino final en Ucrania, es una historia en si misma que dejamos para algún anecdotario futuro. El lado positivo de nuestra llegada fue la habilidad con que nuestro rentista, un profesor del mismo departamento universitario en el cual enseñé, hizo los contactos con los poderes habidos para que nuestra hija pudiera asistir al jardín infantil a sólo pasos del edificio de departamentos en que vivimos. Sin embargo, este feliz arreglo para nuestra hija implicó vivir en un barrio residencial de gente de trabajo, alejados del centro de la ciudad en donde se ubica la Universidad. Por esta razón, aparte de mi trabajo en la Universidad, todas mis actividades en Ucrania se desarrollaron en medio de ciudadanos ucranianos sin mayor contacto previo con occidentales. Algunos vecinos concluyeron que mi esposa, por la apariencia y el acento con que hablaba el ruso, debía ser estoniana, en cuanto a mí, concluyeron que era turco. En cuanto a nosotros, siempre nos fue difícil prefigurar cual nacionalidad nos permitiría caer en mejor gracia con los ucranianos.

\section{La Universidad}

La primera sorpresa en la Universidad no fue para mi sino para mis anfitriones. Resultó que el profesor visitante "americano" no era tal, sino un genuino "latinoamericano." Supongo que algunos colegas ucranianos se sintieron insultados por el hecho de que un programa de apoyo con académicos "americanos" les haya enviado a este subdesarrollado "latinoamericano" como representante de los estándares académicos occidentales, no obstante mis credenciales académicas "americanas." Sin embargo, sí sé que algunas colegas ucranianas se sintieron muy contentas: las profesoras del departamento de Castellano. Resulta, que como parte de un esfuerzo de la Universidad por abrirse al mundo exterior, se había creado el año anterior un programa de Castellano y cultura hispana. El hecho de que fueran profesoras mujeres revela un tanto el estatus del Castellano comparado con los idiomas Inglés, Alemán, y Francés que eran los otros idiomas considerados «internacionales»; Ruso y Polaco eran considerados idiomas «locales.» Por lo tanto, adicionalmente a mis deberes originales con el departamento de Relaciones Econó- 
micas Internacionales, hube de involucrarme en la consolidación de este nuevo programa. Esta inesperada situación me fue extremadamente útil, pues me permitió comunicarme sin barreras lingüísticas en materias delicadas, más allá de lo que podía hacerse en inglés en la Universidad o en ruso-ucraniano por mi esposa en el vecindario.

El edificio principal de la Universidad es un hermoso ejemplo del esplendor del estilo Vienés de la época del Imperio Austro-Húngaro. En el interior, la belleza arquitectónica se olvida dado el deterioro y pésima mantención. Este hecho es significativo porque ilustra características comunes de la realidad ucraniana. Primero que nada, todo lo bello e impresionante que puede encontrarse proviene de una época anterior a la revolución bolchevique. Incluso hermosa publicidad turística impresa durante la era soviética, con muy pocas excepciones, sólo muestra vistas de cultura anterior a la revolución, incluyendo extenso material acerca de arquitectura y arte religioso. Es como si los ucranianos estuvieran muy conscientes de que nada de interés, u orgullo nacional, especialmente en comparación con Occidente, se ha hecho desde 1917. En segundo lugar, en la Ucrania occidental, que fue parte del Imperio Austro-Húngaro, pareciera que el prestigio de aquel imperio crece con el tiempo, cada vez más después de cada nueva experiencia política ocurrida desde entonces. A pesar de que los ucranianos pelearon muy duro por su independencia del imperio Austro-Húngaro y que en su búsqueda por identidad nacional muchas veces se han expresado negativamente acerca de aquel imperio, todo ucraniano educado considera que los Austro-Húngaros fueron gobernantes duros, pero a la vez los más justos que han tenido. Tercero, el concepto de mantención, que siempre he considerado mala en la administración latinoamericana tanto pública como privada, es casi inexistente en la práctica administrativa ucraniana. Dados arraigados hábitos culturales y la falta de prioridad dada al concepto por los burócratas administrativos de la época de la economía centralmente planificada, la falta del concepto de mantención es una seria debilidad para una sociedad como la ucraniana que aspira a niveles de vida occidentales.

Trabajar académicamente sin fácil acceso a computadores es difícil, sin siquiera una sola fotocopiadora en toda la Universidad es heroico. La falta de materiales de trabajo es abismante. Sin embargo, aprendimos algunas lecciones tecnológicas. Primero, contrariamente a lo esperado, dada la realidad ambiente, es más fácil introducir computadores que fotocopiadoras. Consecuen- 
temente con lo ya argumentado, había computadores trabajando porque éstos requieren de menos mantención que las fotocopiadoras. Segundo, cuando se desea estudiar una lengua extranjera, la tecnología sofisticada es un lujo irrelevante. Mis alumnos ucranianos eran inmensamente superiores en idiomas extranjeros a los alumnos que he tenido en los Estados Unidos, no obstante la facilidad de acceso a tecnología avanzada por parte de estos últimos. En Ucrania, en clases de castellano, sólo vi al profesor, lápices de grafito, y cuadernos escolares del tipo usado en Latinoamérica durante los años cincuenta; los pizarrones que no se podían usar adecuadamente dada la falta de mantención, tiza, y almohadilla. Tercero, a pesar de la calidad y el esfuerzo de muchos alumnos y profesores, la educación superior ucraniana será inferior a la occidental durante mucho tiempo más. Esto es así incluso en comparación a la educación superior latinoamericana. En gran parte esto se debe a la falta de recursos, mucho más tiempo pero la adecuada dotación de recursos tomará que el cambio de procedimientos y hábitos académicos arraigados en las aulas universitarias.

Nada ilustra mejor la falta de tradición académica que la absoluta carencia de estándares académicos en ciencias sociales, derecho, y filosofía. Esta clase de disciplinas se cultivaron en el pasado con el objetivo expreso de servir a la ideología oficial del Estado Soviético. Investigación, crítica, e incluso discusión académica eran ajenas al quehacer académico en estas disciplinas. Agrégase a esto el que Ucrania ha iniciado desde su independencia de la Unión Soviética, en agosto de 1991, un serio esfuerzo por utilizar la lengua ucraniana en todos los niveles de la enseñanza. El esfuerzo ha sido exitoso a pesar de que en ciertas regiones el ruso todavía es la lengua predominante y a que todavía existe confusión entre los padres acerca de sí los niños deben aprender ruso, por si acaso, u olvidarse del ruso y concentrarse en que aprendan inglés. Para los efectos académicos prácticos, el problema es que hasta mediados de la presente década ni siquiera han existido textos de estudio en idioma ucraniano. Las bibliotecas son escasísimas y los libros son en su mayoría en ruso y anticuados.

En medio de este astringente medio académico, los estudiantes son una anormalidad. Nunca encontré un alumno que no pensara y soñara en términos y de acuerdo a estándares occidentales. Algunos eran brillantes, otros no serían capaces de pasar los estándares de la academia occidental, pero en términos de mentalidad es significativo que todos ellos pensaran en la línea de 
patrones culturales occidentales y no de acuerdo a la tradición académica nativa.

La mayoría de los profesores se sienten incómodos, vacilando entre el punto de vista de los alumnos y un vago sentimiento de lealtad para con el pasado. Algunos académicos tratan de entender el pasado a fin de enfrentar el futuro; otros añoran el sentido de seguridad que les proveía el antiguo orden. En los viejos tiempos, había que dirigirse a profesores y otros profesionales de respeto por el nombre de pila más el patronímico, un nombre derivado del nombre del padre. Hoy en día, muy pocos observan estas maneras, pero los profesores todavía gozan de respetabilidad social. Sin embargo, está situación esta cambiando rápidamente porque las nuevas generaciones difícilmente pueden concebir la profesión académica como una que pueda satisfacer sus aspiraciones económicas.

\section{El campo, siempre el campo}

El lugar que realmente me enseñó acerca de la sociedad ucraniana fue el campo. Lo que veía en las ciudades comenzó a tener sentido para mí cuando visitando villas museos y villas rurales contemporáneas. Viejas y nuevas villas rurales proyectan un sentido de orden y cuidado. Un orden preindustrial, sin las comodidades modernas, pero un orden social estable y balanceado.

A comienzo de los ochenta, en mis estudios de graduado en Chile, fui introducido a la disciplina de la Ciencia Política Comparada. La idea era utilizar un modelo funcional que permitiera comparar el acontecer político de distintas sociedades, por ejemplo los Estados Unidos y la Unión Soviética, y examinar el supuesto paralelismo de los procesos políticos. Por ejemplo, recuerdo el estudio comparado de la carrera de los generales vencedores Zhukov y McArthur, en la Unión Soviética y los Estados Unidos respectivamente, después de la Segunda Guerra Mundial. Este estudio de caso me causó una profunda insatisfacción. Tratar de establecer un paralelismo paradigmático entre los dos personajes, sobre la base de ciertas similaridades, sin considerar el diferente contexto socio-político, simplemente me pareció una extrapolación infundada a través de la cual el cientista político vacía de todo significado a los hechos históricos. Enfrentado a este tipo de análisis, llegué a la conclusión, entonces audaz y contraria a la opinión de mis profesores, de que la Unión 
Soviética no era una sociedad moderna. Simplemente, no tenía sentido para mí puntualizar que la esclavitud en los Estados Unidos y la servidumbre en Rusia fueron abolida en la misma década, en circunstancias de que la esclavitud afectaba a una pequeña proporción de la población en una sociedad ya capitalista y la servidumbre afectaba a la gran mayoría de la población en una sociedad todavía preindustrial.

Mientras más aprendí de los efectos de la comunicación de Ǔcrania, más entendí mi propia conclusión, un tanto intuitiva, de mis años de alumno en un programa de postgrado. Mi nueva conclusión es un poco más sofisticada: Ucrania es una sociedad industrial, pero no moderna. Estoy consciente de que estamos en la era del postmodernismo y que el mero uso del concepto modernidad me expone a severas críticas y más de alguien considerará ideal la alternativa de una sociedad industrial no moderna. Sin embargo, hoy en día, aún cuando es materia de debate el si las sociedades más avanzadas se encaminan al abismo o están abriendo nuevas fronteras a la humanidad, lo cierto es que los artefactos, procedimientos, y valores que ellas utilizan son el epítome de la modernidad. Y, los patrones que estas sociedades establecen son los que otras tratan de alcanzar. Al respecto, la sociedad ucraniana no es diferente, pero se encuentra en la paradójica situación de ser una sociedad avanzada en términos de industrialización pesada, pero carente de los procedimientos, valores, y comodidades de la modernidad.

La industrialización ucraniana es el resultado de un gran experimento social impuesto sobre Ucrania. De acuerdo a los teóricos bolcheviques de los años veinte, el único camino rápido e igualitario de industrialización de la Unión Soviética era el de la extracción directa de excedente desde el sector agrícola de la economía con el fin de alimentar a los trabajadores industriales de las ciudades. Ucrania fue elegida como el lugar perfecto para el experimento: la California de la Unión Soviética. En Ucrania había sesenta millones de bien alimentados campesinos listos para ser transformados en obreros, sea de la nueva industria pesada o de las granjas colectivas. En 1993, fui testigo del sextuagésimo aniversario de la colectivización agraria ucraniana. El costo humano de la experiencia fue increíble y obvio. La televisión ucraniana no tuvo que fabricar evidencia del costo, simplemente hizo amplio despliegue de material fílmico ruso de la década de los treinta que mostraba los "logros de la revolución." Los académicos todavía discuten las cifras del monto de pérdida de vidas humanas, las cuales varían entre siete millones 
según algunos investigadores occidentales a veinte millones de acuerdo a algunos investigadores ucranianos. En términos económicos, en los ochenta Ucrania alimentaba a duras penas a una población de poco más de cincuenta millones y carecía en cantidad y calidad de bienes de consumo modernos. $Y$, aquí tenemos al pueblo ucraniano, liberado de la servidumbre en los sesenta del siglo XIX, obligado a transformase en obreros industriales durante los treinta del siglo $\mathrm{XX}$, y ahora sobreviviendo el caos económico de la era postsoviética. ¿Cuándo ha tenido tiempo de aprender modernidad? ¿Y, a quién le importaría? En mis años de formación universitaria en Latinoamérica se me enseñó que modernización e industrialización eran fenómenos simbióticos. Bueno, Ucrania me demostró duramente que ese no es siempre el caso.

En Ucrania vi un fracaso absoluto del modelo de industrialización comunista. La economía centralmente planificada fue capaz de construir en Ucrania una inmensa y poderosa máquina de producción industrial pesada sobre la base de una economía de guerra. Pero, sin ninguna consideración por la demanda, más allá de lo que los planificadores decidían debía ser la necesidad de los trabajadores, la economía fracasó miserablemente en proveer los bienes y servicios básicos de consumo de una sociedad moderna. El colapso fue completo cuando la economía fue incapaz de generar e incluso utilizar adecuadamente tecnología avanzada en escala masiva.

El colapso de la economía planificada fue también el fin de todo orden económico en Ucrania. Toda la economía ucraniana no era sino una inmensa unidad de producción de trigo, azúcar, acero, y equipo militar pesado, incluyendo cohetes y misiles, de acuerdo a cuotas de producción y precios determinados en el plan diseñado en Moscú. Sin un "Plan" y sin experiencia previa con el mercado, tuve la impresión de que la sociedad, como un todo, de alguna forma trataba inconscientemente de replicar el "Plan." En una economía en donde el único mercado real es el de la calle y en la que nadie respeta la moneda nacional, ${ }^{1}$ la gente volvió a instituciones mercantiles precapitalistas en medio de una gigantesca y rápidamente obsoleta infraestructural industrial.

En medio de este colapso económico, el campo juega una vez más un papel crucial. Toda familia ucraniana tiene algún tipo de contacto con el área rural, a veces poseyendo su propia parcela, única forma de propiedad agrícola

"En septiembre de 1996 el gobierno introdujo una nueva moneda, la "hryvna," con el fin de reemplazar la "karbovantsy" (comúnmente conocida como "cupones," lo cual demuestra el respeto que merecía), que se habia desvalorizado en un $98 \%$ desde su introducción cinco años atrás. 
permitida, y este contacto es una suerte de proveedor de alimentos básicos. Mediante la conexión agrícola y el intercambio directo de bienes y servicios, la gente común se vio menos afectada por la hiperinflación de lo que he experimentado en Latinoamérica, lo cual tiene sentido dado el mayor grado de monetarización de las economías latinoamericanas.

Ucrania carece de una economía realmente monetaria. Este hecho afecta mucho la estimación de la situación de la economía real de Ucrania. Por ejemplo, de acuerdo a estadísticas internacionales oficiales, la declinación de la economía ucraniana fue dramática. ${ }^{2}$ Bueno, viviendo allá, siempre tuve la impresión de que en términos de cantidad de bienes disponibles, no así en calidad, la situación era mucho mejor de lo que las estadísticas decían, pero el caos económico era inmenso y los costos de transacción se situaban a niveles simplemente impensables en Occidente.

Un sector económico en donde la cantidad disponible ciertamente no es problema es servicios sociales. Dado que éramos una familia viviendo durante un año, tuvimos bastante experiencia con el sistema educacional y de salud. El Estado Ucraniano provee de una amplia oferta de edificios y personal: escuelas, hospitales, profesores, médicos, enfermeras; pero dada la terrible situación financiera y organizacional, la calidad de los servicios es miserable. Servicios de vivienda, transporte, electricidad, agua potable, no son mejores.

La industrialización-urbanización forzosa y la larga experiencia con una economía de la escasez han dejado curiosos hábitos culturales en la población ucraniana. Por ejemplo, siempre me sorprendió el agudo contraste entre conducta pública y privada de los ucranianos. En la vida pública son extremadamente rudos, de acuerdo a estándares estadounidenses y latinoamericanos, pero una vez en el seno de sus hogares, nunca he sido testigo de mayores muestras de afabilidad y generosidad que en Ucrania. A mí me parece que la exclusión directa del consumo moderno, vía escasez de la economía planificada, en lugar de la exclusión anodina vía precios de la economía de mercado, transformó a estos campesinos en peleadores de la calle en su búsqueda de bienes y servicios esenciales. Pero ellos mantienen viva la calidez de la vida campesina y la camaradería de la sociedad preindustrial en la privacidad de sus pequeños departamentos urbanos.

2 El producto nacional bruto declinố en $15 \%$ promedio por año entre 1990 y 1995 , la producción industrial en más de $50 \%$ durante el mismo período. 


\section{El Futuro}

El futuro de Ucrania tiene un claro sabor político. La política doméstica e internacional definirán el futuro de este país. Ucrania tiene los recursos naturales y una población inteligente y trabajadora, pero los desarrollos políticos definirán el sistema social y por ende la forma en que esos recursos serán utilizados. La historia política ha sido extremadamente dura con los ucranianos; cogidos en medio de centenarias luchas geopolíticas, nunca han tenido la oportunidad de construir su propio futuro. Esta puede ser su oportunidad.

El júbilo y el entusiasmo por la independencia de la Unión Soviética ya pasó. Hoy en día la población goza de una libertad política como nunca antes, pero sin la experiencia histórica de libertad y democracia les es difícil imaginarse el futuro político. La sociedad necesita desesperadamente un sistema político moderno y una sociedad civil que interactúe con él, pero ni uno ni otro está en pié todavía.

La vida política de cada día en Ucrania es un asunto de poder personal directo. Sin una historia de partidos políticos que provean cierta base ideológica y organizacional para el debate y competencia política, la lucha política es una lucha directa entre personalidades de viejos clanes de la era soviética, e incluso anteriores, tratando de preservar o mejorar posiciones de poder. El clamor político que más frecuentemente escuché entre mis alumnos y colegas fue la necesidad del "imperio de la ley." Ellos eran perfectamente conscientes que una sociedad sin un Estado de Derecho no puede aspirar a transformarse en una sociedad moderna. La capacidad que tengan los ucranianos para establecer un sistema político fundado en el imperio de la constitución y la ley serán claves para los efectos de asegurarles un porvenir material y una identidad nacional.

Las reformas han sido extremadamente lentas en Ucrania desde la independencia en 1991 y los primeros cinco años fueron un desastre económico. La economía aún casi carece de transparencia y en gran parte es extraoficial. La administración del Presidente Leonid Kuchma ha hecho un serio esfuerzo de modernización. Sin embargo, enfrenta una fuerte oposición por parte del Partido Comunista Ucraniano. Más exitoso ha sido el actual gobierno en sus tratativas con la Federación Rusa. Después de fuertes tensiones a mediados de la presente década, parece que Rusia y Ucrania se encaminan hacia una política de buena vecindad. 


\section{Bibliografía: \\ Oscar Plaza.}

Reflexiones acerca de la vida de cada día en la Ucrania post-sovietica.

Bodie, William C. (1992) "Strategy and

Stccesor States: Report from Kiey,"

World Affairs 154:3.

Koropeckyj, I.S. (1991) Ukrainian Economic History. Interpretative Essays, Cambridge, Mass.: Cambridge University Press.

Kurio, Taras (1995)

Ukrainian Security Policy,

Westport, Conn: Praeger.

Simon, Gerhad (1992)

"The Ukraine and the End of the Soviet Union," Aussenpolitik 43:1

Tedstrom, John E. (1996)

Ukrainian Reforms and Western Assistance:

Struggling together to stay the course.

Santa Monica, CA: Rand. 